\title{
Evaluation of Methods for Dissemination of Prostate Cancer Survivorship Guidelines: A Survey of Primary Care Providers"
}

\author{
Shawn J. Mendonca ${ }^{2}$, Manijeh Berenji ${ }^{3}$, Conrad M. Tobert ${ }^{2}$, Heather Stetler ${ }^{1}$, Deb Bisel ${ }^{1}$, \\ Brian R. Lane 1,2\# $^{\text {,\# }}$ \\ ${ }^{1}$ Cancer Program, Spectrum Health Hospital System, Grand Rapids, USA \\ ${ }^{2}$ Department of Surgery, Michigan State University College of Human Medicine, Grand Rapids, USA \\ ${ }^{3}$ Department of Epidemiology, University of Michigan, Ann Arbor, USA \\ Email: "brian.lane@spectrumhealth.org
}

Received April 2, 2013; revised May 5, 2013; accepted May 13, 2013

Copyright (C) 2013 Shawn J. Mendonca et al. This is an open access article distributed under the Creative Commons Attribution License, which permits unrestricted use, distribution, and reproduction in any medium, provided the original work is properly cited.

\begin{abstract}
Objectives: To assess potential knowledge gaps between primary care providers (PCPs) and cancer specialists, Michigan Cancer Consortium guidelines were developed and disseminated statewide. We evaluated the impact of dissemination of these guidelines on PCP attitudes and beliefs regarding management of prostate cancer (PC) post-treatment sequelae. Methods: Guidelines were disseminated via hard-copy and web-link mailed to 12,000 Michigan PCPs in 2009, and via 5 CME presentations to 181 PCPs in 2010-2011. 132 initial surveys were collected from CME attendees and 549 follow-up surveys were received 20 months after the initial mailing. Results: Surveyed PCPs indicated erectile dysfunction (88\%), incontinence (84\%), anxiety $(54 \%)$ and fear of the unknown $(50 \%)$ as frequent post-treatment sequelae. A minority of PCPs $(\leq 41 \%)$ felt "very comfortable" assessing PC patients for ten post-treatment sequelae at the initial survey, which increased by up to $27 \%$ on follow-up survey. $93 \%$ of PCPs that received guidelines by mail and CME presentation had incorporated them into practice, compared with $72 \%$ of PCPs that received guidelines solely by mailing. Similarly, a greater proportion reported practice pattern changes $(65 \%$ vs. $34 \%, p=0.0003)$. A higher proportion felt CME events (69\% vs. $57 \%$ ) and expert presentations (64\% vs. $44 \%)$ were "very effective", when comparing attendees and non-attendees. Conclusions: Guideline distribution resulted in increased comfort with survivorship issues and incorporation into the practices of the majority of PCPs surveyed. A greater impact was observed in PCPs that attended a CME presentation than in those that received guidelines only by mailing.
\end{abstract}

Keywords: Prostate Cancer; Survivorship; Survey; Primary Care Physicians; Guidelines

\section{Introduction}

Prostate cancer (PC) is the most common non-skin malignancy diagnosed in US men and second leading cause of cancer-related deaths. [1] As the number of deaths from PC continues to decline, the number of survivors is increasing [1,2]. More than 2 million US men with PC are alive today, and the number of survivors is expected to double by $2050[1,3]$. Given the increasing life expectancy of men with PC, national attention has now fo-

\footnotetext{
*The study was supported with funding from the Blue Cross Blue Shield of Michigan (BCBSM) Foundation and the Prostate Cancer Income Tax Check-Off Fund, administered by the Michigan Department of Community Health (MDCH). The contents of the publication do not necessarily represent the official views of the BCBSM Foundation or the $\mathrm{MDCH}$. There are no financial disclosures for any authors. ${ }^{\#}$ Corresponding author.
}

cused on the survivorship phase of the cancer trajectory. In 2005, the Institute of Medicine (IOM) prepared a comprehensive report on cancer survivorship [4]. As the report highlights, the transition from active treatment to post-treatment care is critical to long-term health. If care is not planned and coordinated, cancer survivors are left unaware of their heightened risks and hence are lost to follow-up, resulting in potentially adverse outcomes [4]. Current emphasis has been placed on improving the quality of cancer survivorship care, including not only surveillance for recurrence, but also general primary and preventive care, as well as care for comorbid conditions $[3,5,6]$. Thus, the development of plans that summarize critical information needed for the survivor's long-term care have been recommended by both the President's 
Cancer Panel and by the IOM committee [4].

Health care professionals are becoming increasingly aware of the long-term consequences of various treatments for PC [7]. Although many patients remain under the care of a specialist following initial treatment, most patients eventually return to a primary care provider (PCP) to coordinate their care and manage various health-related concerns, due in part to a lack of specialist availability to respond to the rapid growth in cancer survivors [8]. In 2009, the Michigan Cancer Consortium (MCC) released "Guidelines for Primary Care Management of PC Post-Treatment Sequelae", which provide substantive descriptors and management options for each sequelae. In this study, we disseminated guidelines to PCPs via hard copy, web links and CME presentations and evaluated the identification of PC survivorship issues, comfort with management of these issues, and preferred methods for communication of the guidelines. We hypothesized that direct mail and internet-based dissemination might increase awareness and incorporation of the MCC guidelines and that facilitating interactions between PCPs and cancer specialists, via CME events, would have an even greater impact.

\section{Materials and Methods}

\subsection{Initial Mailing of MCC Guidelines to Michigan PCPs}

12,000 physicians with a Michigan medical license and Michigan mailing address were identified from a statewide database maintained by a private vendor and verified using data from the Michigan Bureau of Health Professionals. The Michigan Department of Community Health (MDCH), in conjunction with the MCC, then mailed informational packets containing an introductory letter, a paper copy of the MCC "Guidelines for Primary Care Management of Prostate Cancer Post-treatment Sequelae", and web link to these guidelines and an additional web link to factsheets of common sequelae to these providers $[9,10]$.

\subsection{Survey Development}

Survey instruments were developed after discussion and interviews with three focus groups of PCPs and revised after consultation with survey development personnel and subsequent pre-testing. The initial (post- presentation)

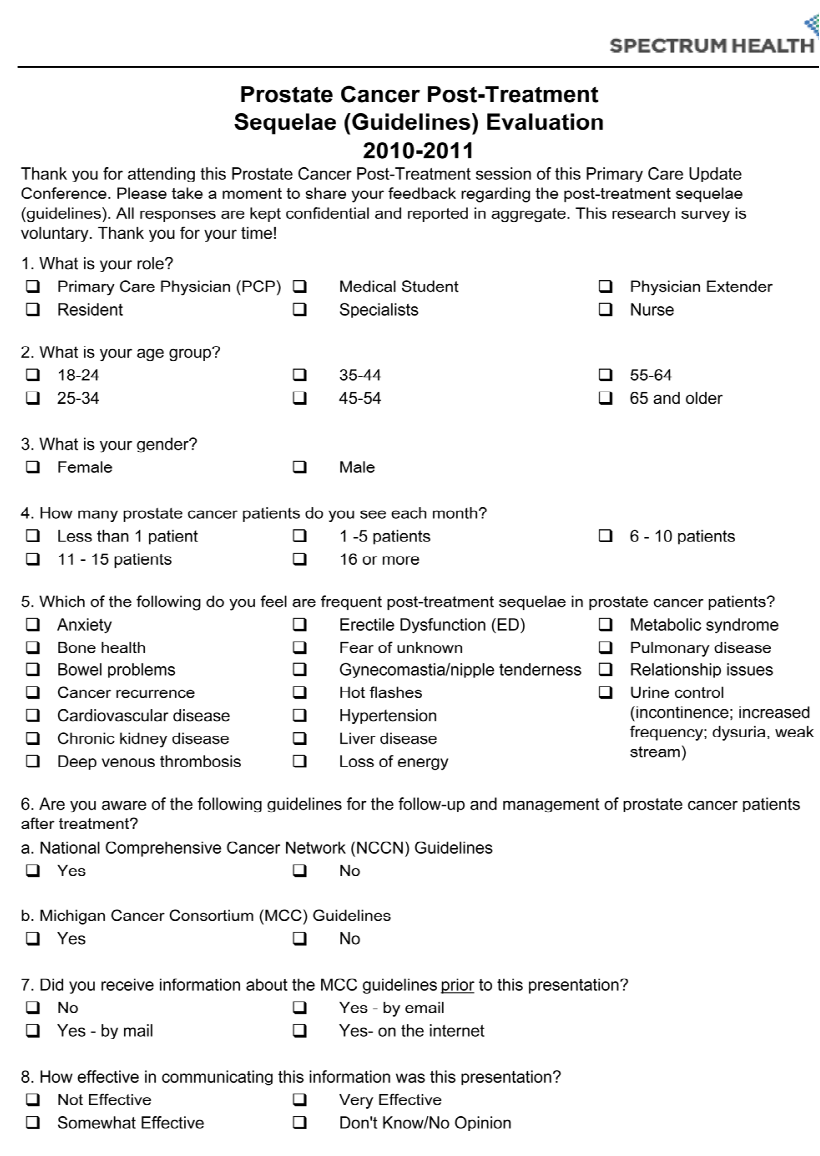

\begin{tabular}{|c|c|c|c|c|c|}
\hline \multicolumn{6}{|c|}{$\begin{array}{l}\text { 9. Please rate how comfortable you are about assessing prostate cancer patients for the following post- } \\
\text { treatment seguelae. }\end{array}$} \\
\hline & $\mid \begin{array}{c}\text { Very } \\
\text { Uncomfortable }\end{array}$ & $\mid \begin{array}{c}\text { Somewhat } \\
\text { Uncomfortable }\end{array}$ & $\begin{array}{c}\text { Somewhat } \\
\text { Comfortable }\end{array}$ & $\left|\begin{array}{c}\text { Very } \\
\text { Comfortable }\end{array}\right|$ & $\begin{array}{l}\text { Don't Knowl } \\
\text { No Opinion }\end{array}$ \\
\hline Recurrence & a & ב & 口 & 口 & a \\
\hline $\begin{array}{l}\begin{array}{l}\text { Erectile dysfunction } \\
\text { (impotence) }\end{array} \\
\end{array}$ & ם & ב & ם & ב & ם \\
\hline $\begin{array}{l}\text { Incontinence (urine } \\
\text { control) }\end{array}$ & ב & ב & ם & $\square$ & ם \\
\hline Bowel problems & ב & ב & प & $\square$ & प \\
\hline Hot flashes & a & ב & ב & a & Q \\
\hline Bone health & ב & ב & ב & ב & प \\
\hline \begin{tabular}{|l|} 
Gynecomastia/nipple \\
tenderness
\end{tabular} & a & ב & 口 & ב & 口 \\
\hline Relationship issues & ב & ב & ב & 口 & a \\
\hline Fear of the unknown & ב & ב & 口 & 口 & 口 \\
\hline Metabolic syndrome & ב & ב & ם & 口 & $\square$ \\
\hline
\end{tabular}

10. We'd like to find out how you prefer to get information. If the following were made more readily available, how effective would that method of communication be to you?

\begin{tabular}{|l|c|c|c|c|}
\multicolumn{1}{l|}{} & Not Effective & $\begin{array}{c}\text { Somewhat } \\
\text { Effective }\end{array}$ & $\begin{array}{c}\text { Very } \\
\text { Effective }\end{array}$ & $\begin{array}{c}\text { Don't Knowl } \\
\text { No Opinion }\end{array}$ \\
\hline $\begin{array}{l}\text { Internet/Online resources } \\
\text { Online access (chat room) to a prostate } \\
\text { cancer expert }\end{array}$ & $\square$ & $\square$ & $\square$ & $\square$ \\
\hline Email access to a prostate cancer expert & $\square$ & $\square$ & $\square$ & $\square$ \\
\hline $\begin{array}{l}\text { Direct phone access to personnel to direct } \\
\text { you to a prostate cancer expert }\end{array}$ & $\square$ & $\square$ & $\square$ & $\square$ \\
\hline Presentation by prostate cancer expert & $\square$ & $\square$ & $\square$ & $\square$ \\
\hline CME events/conferences & $\square$ & $\square$ & $\square$ & $\square$ \\
\hline $\begin{array}{l}\text { One-to-two page "state-of-the-science" } \\
\text { sheets }\end{array}$ & $\square$ & $\square$ & $\square$ & $\square$ \\
\hline Pocket card with MCC guidelines & $\square$ & $\square$ & $\square$ & $\square$ \\
\hline List-serve & $\square$ & $\square$ & $\square$ & $\square$ \\
\hline
\end{tabular}

11. As a reminder, you will receive a $\$ 25$ gift card after completing a follow-up survey (regarding the impact on your practice) in approximately 6 months. Please print your name and specify below what's the best way to follow-up with you.

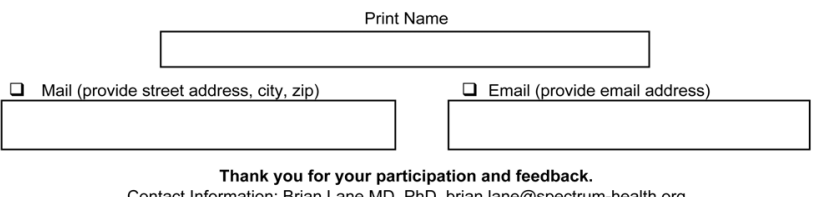

Thank you for your participation and feedback.
Contact Information: Brian Lane MD, PhD brian.lane@spectrum-health.org

Figure 1. The initial (post-presentation) survey that was distributed immediately after the CME presentation. 
SPECTRUM HEALTH

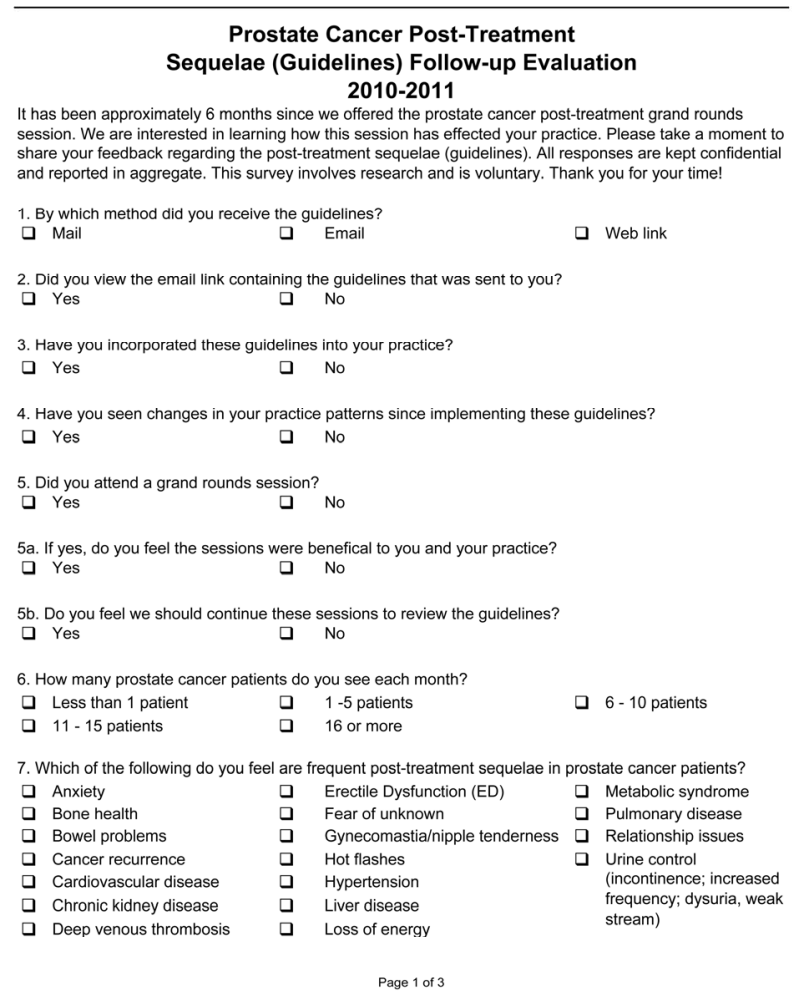

SPECTRUM HEALTH

\begin{tabular}{|c|c|c|c|c|c|}
\hline \multirow{2}{*}{\multicolumn{6}{|c|}{$\begin{array}{l}\text { 8. Have you used the following guidelines for the follow-up and management } \\
\text { after treatment? }\end{array}$}} \\
\hline \multirow{2}{*}{\multicolumn{6}{|c|}{ a. National Comprehensive Cancer Network (NCCN) Guidelines }} \\
\hline & & & & & \\
\hline \multicolumn{6}{|c|}{ b. Michigan Cancer Consortium (MCC) Guidelines } \\
\hline \multicolumn{6}{|c|}{ a Yes a No } \\
\hline \multicolumn{6}{|c|}{$\begin{array}{l}\text { 9. Please rate how comfortable you are about assessing prostate cancer patients for the following post- } \\
\text { treatment sequelae. }\end{array}$} \\
\hline & $\begin{array}{c}\text { Vory } \\
\text { Uncomfortable }\end{array}$ & $\left|\begin{array}{c}\text { Somewhat } \\
\text { Uncomfortable }\end{array}\right|$ & $\begin{array}{l}\text { Somewhat } \\
\text { Comfortable }\end{array}$ & $\left|\begin{array}{c}\text { Very } \\
\text { Comfortable }\end{array}\right|$ & $\begin{array}{l}\text { Don't Knowl } \\
\text { No Opinion }\end{array}$ \\
\hline Recurrence & $\square$ & 0 & 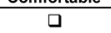 & $\square$ & 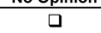 \\
\hline $\begin{array}{l}\begin{array}{l}\text { Erectile dysfunction } \\
\text { (impotence) }\end{array} \\
\end{array}$ & ב & ב & ם & ם & ם \\
\hline $\begin{array}{l}\text { Incontinence (urine } \\
\text { control) }\end{array}$ & $\square$ & $\square$ & $\square$ & ם & a \\
\hline Bowel problems & 口 & 口 & ב & 口 & 口 \\
\hline Hot flashes & a & 口 & a & a & ב \\
\hline Bone health & ב & ב & ב & ם & ב \\
\hline $\begin{array}{l}\text { Gynecomastia/nipple } \\
\text { tenderness }\end{array}$ & $\square$ & a & ב & ם & ם \\
\hline Relationship issues & a & 口 & ב & 口 & a \\
\hline Fear of the unknown & 口 & 口 & ב & a & ב \\
\hline Metabolic syndrome & a & ב & ב & a & a \\
\hline
\end{tabular}

0. We'd like to find out how you prefer to get information. If the following were made more readily available, how effective would that method of communication be to you?

\begin{tabular}{|l|c|c|c|c|}
\multicolumn{1}{l|}{} & Not Effective & $\begin{array}{c}\text { Somewhat } \\
\text { Effective }\end{array}$ & $\begin{array}{c}\text { Very } \\
\text { Effective }\end{array}$ & $\begin{array}{c}\text { Don't Knowl } \\
\text { No Opinion }\end{array}$ \\
\hline expert presentation by prostate cancer & $\square$ & $\square$ & $\square$ & $\square$ \\
\hline Email access to a prostate cancer expert & $\square$ & $\square$ & $\square$ & $\square$ \\
\hline Internet/Online resources & $\square$ & $\square$ & $\square$ & $\square$ \\
\hline CME events/conferences & $\square$ & $\square$ & $\square$ & $\square$ \\
\hline $\begin{array}{l}\text { One-to-two page "state-of-the-science" } \\
\text { shets }\end{array}$ & $\square$ & $\square$ & $\square$ & $\square$ \\
\hline List-serve & $\square$ & $\square$ & $\square$ & $\square$ \\
\hline $\begin{array}{l}\text { Direct phone access to personnel to direct } \\
\text { you to a prostate cancer expert }\end{array}$ & $\square$ & $\square$ & $\square$ & $\square$ \\
\hline Pocket card with MCC guidelines & $\sqcup$ & $\sqcup$ & $\sqcup$ & $\sqcup$ \\
\hline $\begin{array}{l}\text { Online access (chat room) to a prostate } \\
\text { cancer expert }\end{array}$ & $\square$ & $\square$ & $\square$ & $\square$ \\
\hline
\end{tabular}

SPECTRUM HEALTH

11. What is your role?

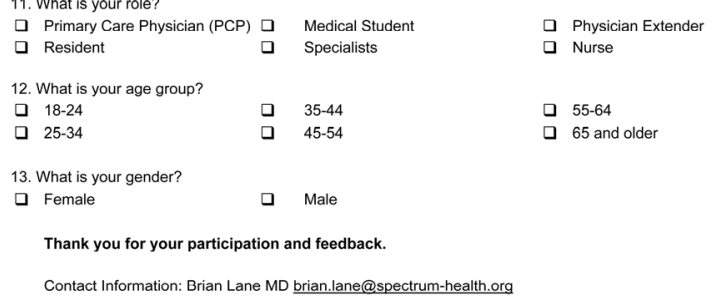

Page 3 of 3

Figure 2. The follow-up survey that was distributed to all PCPs that received guidelines via mail.

survey (Figure 1) and follow-up survey (Figure 2) consisted of 11 and 13 items, respectively. Comfort with assessment of each sequelae was assessed using a 4-point Likert scale with a "don't know/no opinion" option. Effectiveness of each method of communication of PC guidelines was assessed using a 3-point Likert scale with a "don't know /no opinion" option.

\subsection{CME Presentations to West Michigan PCPs}

Five separate CME events for PCPs from an 8-county area in West Michigan were given by one urologic cancer specialist and member of the MCC Prostate Cancer Action Committee between July 2010 and March 2011. To evaluate the breadth of PC knowledge, PCPs were administered a pre-lecture knowledge assessment that consisted of six multiple-choice questions (Figure 3) via hard-copy or audience response system. A 40-minute presentation regarding PC survivorship issues, recommendations for initial management and indications for referral preceded administration of the initial survey.

\subsection{Follow-Up Surveys to Michigan PCPs}

The follow-up survey instrument was disseminated to all Michigan physicians in May 2011 using the same vendor who provided the original list. The follow-up packet included a cover letter indicating that the survey was intended for PCPs, link to web-based content, the followup survey, a laminated copy of the guidelines and a postage-paid return envelope to the data manager $[9,10]$. A $\$ 25$ gift card was provided upon completion of the paper or on-line survey. Approximately 2 weeks later, a second copy of the survey was sent to non-respondents. A third attempt to contact non-respondents was made by email 2 weeks later.

\subsection{Statistical Analysis}

Descriptive statistics were used to evaluate the survey responses, using the total number of responses per survey 
SPECTRUM HEALTH

\section{Prostate Cancer Knowledge Assessment}

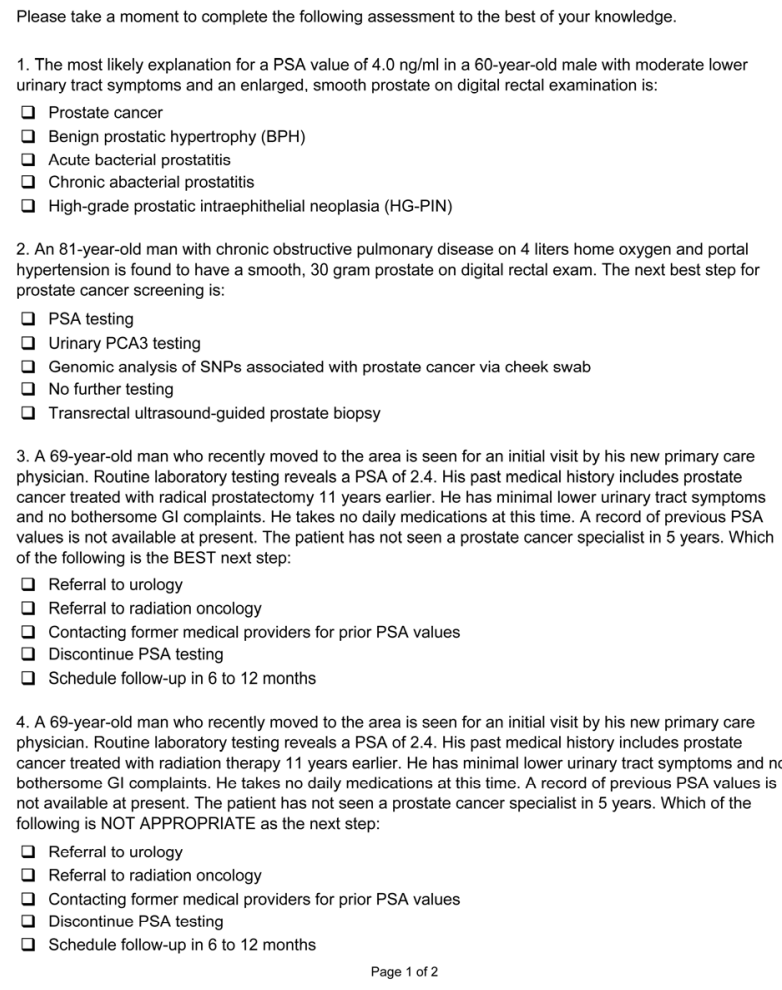

3. A 69-year-old man who recently moved to the area is seen for an initial visit by his new primary care physician. Routine laboratory testing reveals a PSA of 2.4 . His past medical history includes prostate cancer treated with radical prostatectomy 11 years earlier. He has minimal lower urinary tract symptoms and no bothersome GI complaints. He takes no daily medications at this time. A record of previous PSA values is not available at present. The pations
of the following is the BEST next step:

SPECTRUM HEALTH

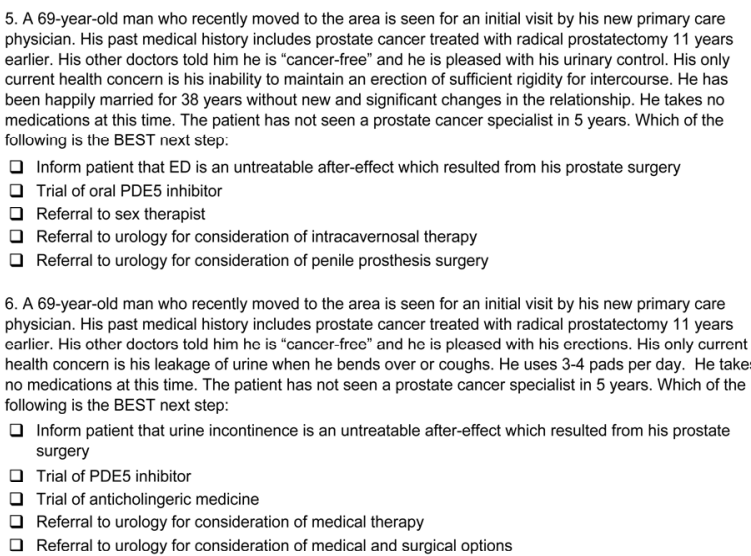

Thank you for your participation. Page 2 of 2

Figure 3. Pre-lecture knowledge assessment that was given to all CME presentation attendees.

item as the denominator. Comparisons of the distribution of categorical variables were made using Pearson chisquare tests with Yates' continuity correction and exact Fisher tests when proportions $<5 \%$ in one or more categories. Statistical significance was assessed based on a two-sided significance level of 0.05 .

\section{Results}

Between 2009 and 2011, the MCC guidelines were distributed by direct mailing of a state-of-the-science sheet, a web link to the guidelines, and CME presentation by a PC expert. Attendance was recorded for 181 individuals at five CME events. A total of 549 follow-up surveys were received, including 55 from individuals who attended a CME event (30\% response rate), at an average of 5 months after the CME events and 20 months after initial mailing. The age demographics of PCPs that completed the follow-up survey were 25 - 34 years $(13 \%), 35$ - 44 years $(24 \%), 45$ - 54 years $(23 \%), 55$ - 64 years $(25 \%)$, and 65 years or older (14\%). There was a $63 \%$ male to $37 \%$ female distribution of those that completed the follow-up survey. The PCPs that completed the survey were composed of MD physicians (59\%), DO physicians $(34 \%)$, and physician assistants and nurse practitioners $(7 \%)$. Survey respondents indicated that the number of PC patients evaluated each month was $<1(30 \%), 1$ - 5 (52\%), 6 - 10 (13\%), 11 - 15 (4\%), and >15 (2\%).

Assessment of PCP knowledge of PC survivorship issues performed immediately prior to CME presentations, via six multiple choice questions, indicated some gaps in understanding. Incorrect responses ranged between $0 \%$ and 67\% (median: 33\%). For example, 64\% did not recognize a PSA value of 2.4 as clear evidence of cancer recurrence after radical prostatectomy and $56 \%$ of respondents did not initially refer a man using 3 - 4 pads per day for stress urinary incontinence to an urologist. On the initial survey, only $40 \%$ and $36 \%$ of individuals were aware of the MCC guidelines and National Comprehensive Cancer Network guidelines for PC, respectively.

On the initial survey, PCPs indicated that ED (88\%), incontinence $(84 \%)$, anxiety $(54 \%)$, and fear of the un-

Table 1. Concerns identified by PCPs as frequent posttreatment sequelae in $\mathrm{PC}$ patients.

\begin{tabular}{ll}
\hline Erectile dysfunction (ED) & $88 \%$ \\
Urine control (incontinence) & $84 \%$ \\
Anxiety & $54 \%$ \\
Fear of the unknown & $50 \%$ \\
Cancer recurrence & $35 \%$ \\
Loss of energy & $33 \%$ \\
Relationship issues & $31 \%$ \\
Hot flashes & $26 \%$ \\
Bowel problems & $26 \%$ \\
Bone health & $19 \%$ \\
Gynecomastia/nipple tenderness & $14 \%$ \\
Metabolic syndrome & $9 \%$ \\
\hline
\end{tabular}

The following unrelated conditions were listed by $7 \%$ or less of 549 PCPs on follow-up survey: cardiovascular disease, deep vein thrombosis, chronic kidney disease, hypertension, liver disease, pulmonary disease. 
Table 2. Comfort level of PCPs in assessing PC patients for individual survivorship issues.

\begin{tabular}{|c|c|c|c|c|}
\hline \multirow[b]{2}{*}{$\begin{array}{l}\text { \% "Very } \\
\text { comfortable" }\end{array}$} & \multirow{2}{*}{$\begin{array}{c}\text { Initial Survey } \\
\text { CME } \\
\text { Attendees } \\
(\mathrm{n}=132)\end{array}$} & \multicolumn{3}{|c|}{ Follow-Up Survey } \\
\hline & & $\begin{array}{c}\text { CME } \\
\text { Attendees } \\
(\mathrm{n}=55)\end{array}$ & $\begin{array}{c}\text { Non- } \\
\text { Attendees } \\
(\mathrm{n}=494)\end{array}$ & $\begin{array}{c}\text { Overall } \\
(\mathrm{n}=549)\end{array}$ \\
\hline Metabolic syndrome & $41 \%$ & $57 \%$ & $60 \%$ & $59 \%$ \\
\hline $\begin{array}{l}\text { Erectile dysfunction } \\
\text { (ED) }\end{array}$ & $34 \%$ & $49 \%$ & $53 \%$ & $52 \%$ \\
\hline Bone health & $26 \%$ & $53 \%$ & $49 \%$ & $49 \%$ \\
\hline Fear of the unknown & $31 \%$ & $37 \%$ & $49 \%$ & $48 \%$ \\
\hline Relationship issues & $34 \%$ & $38 \%$ & $47 \%$ & $46 \%$ \\
\hline Bowel problems & $26 \%$ & $44 \%$ & $42 \%$ & $43 \%$ \\
\hline $\begin{array}{l}\text { Urine control } \\
\text { (incontinence) }\end{array}$ & $30 \%$ & $43 \%$ & $38 \%$ & $38 \%$ \\
\hline Cancer recurrence & $22 \%$ & $38 \%$ & $38 \%$ & $38 \%$ \\
\hline Hot flashes & $18 \%$ & $33 \%$ & $30 \%$ & $30 \%$ \\
\hline $\begin{array}{l}\text { Gynecomastia/ } \\
\text { nipple tenderness }\end{array}$ & $15 \%$ & $29 \%$ & $28 \%$ & $28 \%$ \\
\hline
\end{tabular}

known $(50 \%)$ were frequent post-treatment sequelae, with other issues identified by $<40 \%$ of respondents (Table 1). Only a minority of individuals mentioned that they were "very comfortable" managing PC post-treatment sequelae (Table 2), with the greatest proportions for metabolic syndrome (40\%), ED (34\%) and relationship issues (32\%). These attendees additionally indicated that the most effective method of communicating PC survivorship issues included internet/on-line resources (77\%), presentation by an expert (73\%), CME events (65\%), pocket card (62\%) and state-of-the-science sheets (58\%). Immediately after the CME event, a majority of surveyed CME attendees $(87 \%)$ felt that the presentation was "very effective", with $11 \%$ responding "somewhat effective" and $2 \%$ not providing an answer.

On the follow-up survey, the proportion of individuals indicating comfort with assessment of PC post-treatment sequelae was higher than at initial survey in all categories (Table 2). The proportions ranged from $28 \%$ to $59 \%$ overall, with the greatest proportions indicating they were "very comfortable" with assessment of metabolic syndrome $(59 \%)$, ED $(52 \%)$, bone health $(49 \%)$, fear of the unknown (48\%), and relationship issues (46\%). Only a small proportion $(<10 \%)$ of PCPs felt "very uncomfortable" managing each PC survivorship issue on follow-up survey. For the subset of CME attendees, the proportions feeling "very comfortable" ranged from $29 \%$ to $57 \%$, with comfort increases between $4 \%$ and $27 \%$ for each sequelae (Table 2). For example, 53\% of CME event attendees indicated they were "very comfortable" assessing for bone health (vs. 26\% initially, $p=0.0009$ ), $44 \%$ for bowel problems (vs. 26\% initially, $p=0.02$ ), $33 \%$ for hot flashes (vs. 18\% initially, $\mathrm{p}=0.06$ ), and $38 \%$ for cancer recurrence (vs. $22 \%$ initially, $\mathrm{p}=0.05$ ). There were no significant differences noted when com-

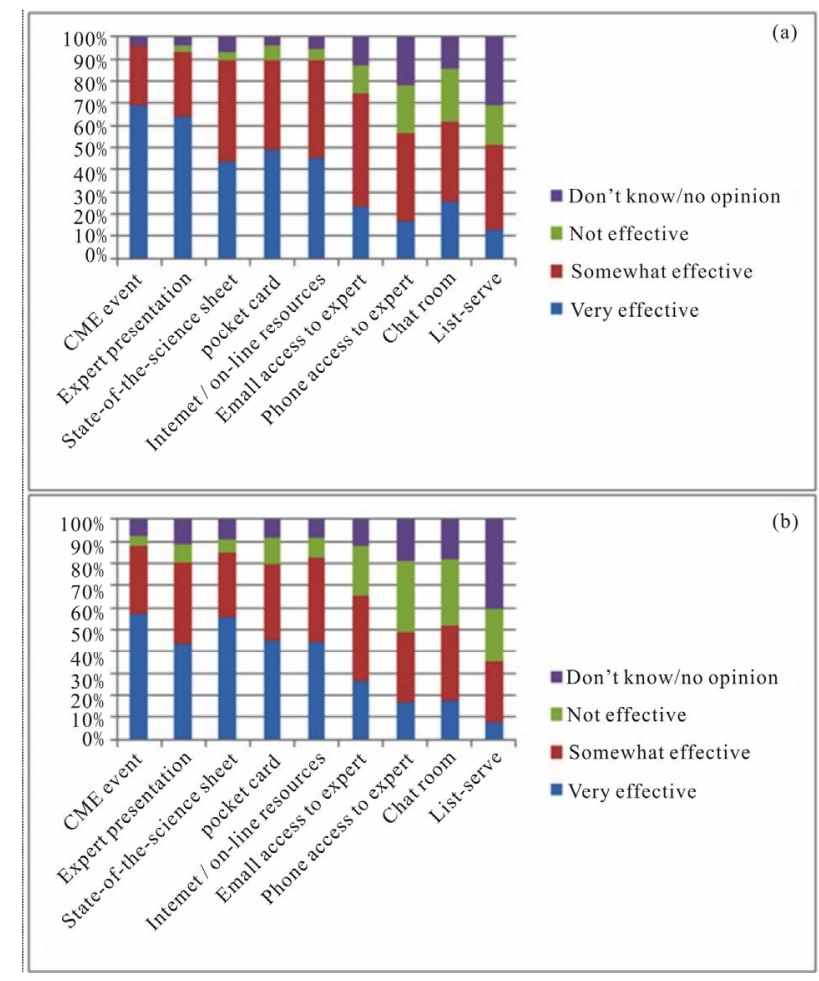

Figure 4. PCP perception of the effectiveness of various methods of communication regarding cancer survivorship of CME attendee (a) and non-attendee (b) follow-up surveys.

paring attendees and non-attendees of a CME event ( $p>$ 0.05 for each) on follow-up survey.

PCPs also evaluated the effectiveness of various communication methods regarding survivorship. For both CME attendees and non-attendees, CME events, expert presentations, state-of-the-science sheets, pocket cards and internet/on-line resources were felt to be "very effective" by a greater proportion than the other four methods (Figure 4). When comparing follow-up survey results between attendee and non-attendee subgroups, a higher proportion felt that CME events (69\% vs. 57\%) and expert presentations ( $64 \%$ vs. $44 \%$ ) were "very effective". When comparing the survey results between attendees and non-attendees, state-of-the-science sheets were found to be "very effective" by a lesser proportion (44\% vs. $55 \%)$. The subgroups did not report different preferences for the remaining methods ( $p>0.05)$.

Assessment of CME events as a method of dissemination of survivorship information revealed widespread support: $95 \%$ of attendees felt the sessions were beneficial to them and their practice. In addition, 98\% indicated that these sessions should continue as a means to receive survivorship care training. At an average of 5 months after attending the event, 93\% of attendees had incorporated the MCC guidelines into their practice, with $65 \%$ of them having seen changes in their practice patterns as a result. 
By comparison, at 20 months after dissemination of print and on-line access to the MCC guidelines, $72 \%$ of those who had been sent the guidelines (but had not attended a CME event) had incorporated the guidelines into their practice $(p=0.004)$ and only $34 \%$ felt they had seen changes in their practice pattern since doing so $(\mathrm{p}=$ $0.0003)$.

\section{Comment}

Training PCPs to care for cancer survivors is increasingly being recognized as a national health concern $[3,4,6]$. In 2006, the Early Detection and Screening for Prostate Cancer Knowledge, Attitudes and Practice (KAP) Survey was conducted by the Michigan Public Health Institute to investigate the beliefs and practice patterns of PCPs in Michigan. This survey indicated that although $67 \%$ of PCPs cared for men during and after PC treatment, only a minority felt "very comfortable" managing post-treatment sequelae [7]. Nearly half (45\%) of PCPs felt it was equally important for PCPs and treating specialists to provide PC survivorship care [7]. However, the surveyed PCPs indicated that clear plans $(76 \%)$ and details regarding the management of post-treatment sequelae $(65 \%)$ provided by specialists were suboptimal [7]. In response to this and to improve the quality and coordination of PC survivorship care, the MCC Prostate Cancer Action Committee created guidelines to assist PCPs in managing PC treatment sequelae [7]. Skolarus and colleagues concluded that "better understanding how best to incorporate these guide lines into practice is needed", suggesting that "good communication with treating specialists... and post-treatment guidelines or care plans may lead to improved quality of care" [7]. The present study examined the impact of dissemination of the MCC guidelines via direct mail, on-line access, and expert presentation on the attitudes and practices of PCPs in Michigan.

The results of this study show that dissemination of the MCC guidelines appears to have had significant impact on PCP attitudes and beliefs. Skolarus and colleagues found that the proportion of physicians that felt "very comfortable" managing ED was $21 \%$ in 2006 , prior to development of MCC guidelines [7]. The proportion of PCPs that felt "very comfortable" managing ED increased to $34 \%$ in 2009-2010 (after initial distribution of MCC guidelines) and to 52\% in 2011 (after additional guideline distribution and CME events). Similarly, the proportion of PCPs "very comfortable" with managing incontinence increased from $12 \%$, to $30 \%$, and then to $38 \%$ at these same time points. It should be noted that the increase in comfort level of PCPs managing prostate cancer sequelae since 2006, could be secondary to increasing prevalence of PC survivorship [1,2], selection biases, and/or ascertainment bias. Nevertheless, the results from this study highlight significant improvements in PCP comfort with survivorship issues in concert with efforts to address this issue by MCC guideline dissemination. For example, at the initial survey, where only $40 \%$ of individuals indicated that they had received MCC guidelines via hard copy and web links, $34 \%$ indicated feeling "very comfortable" in managing ED. At the follow-up survey, after dissemination of MCC guidelines via a CME event to these PCPs, $49 \%$ of individuals felt "very comfortable" in managing ED. Increases in the proportions of PCPs feeling "very comfortable" were also noted in management of urinary incontinence at $30 \%$ and $43 \%$, respectively. Ultimately, the results show that dissemination of MCC guidelines, whether in the form of hard copy and web links or an additional CME event, leads to an increase in comfort level of PCPs for all post-treatment sequelae assessed (Table 2).

In determining the best tool(s) for guideline dissemination, the follow-up survey respondents indicated that CME events, such as presentation by a PC expert, were the most preferred means of receiving new information regarding PC survivorship care. Our data is consistent with prior investigations of the impact of CME for PCPs $[11,12]$. For example, Allaire et al. found that $87 \%$ of attendees reported that a CME event about blood pressure management positively impacted their practice. However, similar to the present study, a low contribution of responses $(24 \%)$ was a main weakness of the study [11]. A significant proportion also preferred state-of- the-science sheets [9], pocket cards, and internet/on-line resources as methods of communication regarding cancer survivorship issues. PCPs expressed the least interest in other forms of communication, such as phone or email access to a PC expert or chat rooms and listservs addressing survivorship issues. When looking at impact of the specific type of information dissemination, the results from the follow-up survey indicate that attendance at a CME event led to greater incorporation of the guidelines $(93 \%$ vs. $72 \%)$ and changes in practice pattern (65\% vs. $34 \%$ ) compared to dissemination by direct mailing and internet resources alone. However, it should be noted, on follow-up survey, that there appears to be no significant differences between $\mathrm{CME}$ attendees and non-attendees when examining PCP comfort level of PC sequelae management. Ultimately, this study analyzes the impact of dissemination of MCC guidelines via hard copy and web links vs. dissemination via hard copy, web links and CME event, which are the preferred dissemination methods of PCPs. Our data suggest that funding agencies should limit support for untested methods, and instead consider allocations to provide resources using the approaches preferred by PCPs, taking into consideration the impact of each method of dissemination on patient management. We suggest that cancer centers and larger can- 
cer care organizations coordinate CME events about cancer survivorship issues for PCPs (and survivors). As a supplemental resource, these organizations should develop and distribute hard-copy cancer care plans and detailed treatment guidelines, and expand on-line content regarding survivorship.

Follow-up surveys from 549 PCPs revealed that PC patients are encountered frequently by PCPs. Our data shows that $71 \%$ of PCPs manage at least $1 \mathrm{PC}$ patient per month, with $19 \%$ managing at least 6 patients monthly. Although some knowledge gap between PCPs and specialists was expected and is suggested by the knowledge assessment performed herein, PCPs appear to be acutely aware of the emotional and psychological aspects of cancer survivorship. Respondents correctly indicated that ED and urinary control are the most frequent sequelae after PC treatment [13], but $\sim 50 \%$ also indicated that fear of the unknown and anxiety are frequent concerns. Those surveyed also indicated that loss of energy and relationship issues occurred as commonly as cancer recurrence. These issues may be inadequately addressed by cancer specialists whose expertise and attention can become directed more to the cancer than the cancer survivor [4]. Based on the identified physical and psychosocial aspects of survivorship [4], we would contend that PC survivorship care will likely be optimized by multi-disciplinary participation of cancer specialists, the patient's PCP and other care providers as needed. Once the post-treatment sequelae have stabilized, it may be appropriate for the PCP to exclusively manage the patient's care provided patient-specific guidelines are received from the specialist and expedited access for re-referral and investigations is available [8,14].

Limitations of the present study consist of the inclusion of PCPs from Michigan rather than a national sample, and the dissemination of guidelines by expert presentation to only a subset of Michigan PCPs. Furthermore, PCPs of the study included an admixture of MD physicians, DO physicians, physician assistants and nurse practitioners. It should be acknowledged that these factors could weaken the generalizability of the study when applied to other parts of the country where demographics, beliefs and practices of PCPs differ. The overall response rate in our study was low, in part because of the study methodology, in which surveys were mailed to all physicians who were encouraged to respond only if they selfidentified as "PCP", rather than targeted specifically to PCPs. Nevertheless, 549 surveys were received, which is similar to the total number of survey responses to other physician survey studies, such as the KAP survey $[3,7$, 15]. Another limitation is that we report the self-assessed beliefs and practice patterns of PCPs rather than the actual survivorship care that patients are receiving. It is uncertain, in our study, whether increasing comfort level with management of various sequelae, and incorporation of guidelines into practice, actually leads to improved outcomes for PC patients. Finally, the reporting of preferred methods of information dissemination may be biased by limited exposure to all method types.

\section{Conclusion}

Distribution of the MCC "Guidelines for the Primary Care Management of PC Post-Treatment Sequelae" by hard copy, internet and CME events were felt to be very effective by the majority of PCPs surveyed. Development and distribution of these guidelines have resulted in incorporation into the practices of the majority of PCPs surveyed and increased comfort in managing PC survivorship issues. The greatest impact was observed in PCPs that attended a CME presentation by a cancer specialist, which was also the most preferred method of information dissemination. Further research is needed to determine if guideline dissemination leads to improved patient outcomes.

\section{Acknowledgements}

The authors would like to thank Carol Garlinghouse, Polly Hager, Nora Maloy, and the MCC Prostate Cancer Action Committee. The authors also extend much appreciation to all of the providers who participated in this survey so that together we can provide optimal survivorship care to our patients.

\section{REFERENCES}

[1] American Cancer Society, "Prostate Cancer Overview," 2012.

http://www.cancer.org/acs/groups/cid/documents/webcont ent/003134-pdf.pdf

[2] B. D. Smith, G. L. Smith, A. Hurria, et al., "Future of Cancer Incidence in the United States: Burdens upon an Aging, Changing Nation," Journal of Clinical Oncology, Vol. 27, No. 17, 2009, pp. 2758-2765. doi:10.1200/JCO.2008.20.8983

[3] S. L. Bober, C. J. Recklitis, E. G. Campbell, et al., "Caring for Cancer Survivors: A Survey of Primary Care Physicians," Cancer, Vol. 115, No. S18, 2009, pp. 44094418. doi:10.1002/cncr. 24590

[4] M. Hewitt, S. Greenfield and E. Stovall, "From Cancer Patient to Cancer Survivor: Lost in Transition. Committee on Cancer Survivorship: Improving Care and Quality of Life, National Cancer Policy Board. Institute of Medicine and National Research Council of the National Academies," National Academy Press, Washington DC, 2005.

[5] C. F. Snyder, K. D. Frick, R. J. Herbert, et al., "Preventive Care in Prostate Cancer Patients: Following Diagnosis and for Five-Year Survivors," Journal of Cancer Survivorship, Vol. 5, No. 3, 2011, pp. 283-291.

doi:10.1007/s11764-011-0181-y 
[6] P. A. Ganz, "Survivorship: Adult Cancer Survivors," Primary Care, Vol. 36, No. 4, 2009, pp. 721-741. doi:10.1016/j.pop.2009.08.001

[7] T. A. Skolarus, M. Holmes-Rovner, L. L. Northouse, et al., "Primary Care Perspectives on Prostate Cancer Survivorship: Implications for Improving Quality of Care," Urologic Oncology: Seminars and Original Investigations, 2011.

[8] C. Erikson, E. Salsberg, G. Forte, et al., "Future Supply and Demand for Oncologists: Challenges to Assuring Access to Oncology Services," Journal of Oncology Practice, Vol. 3, No. 2, 2007, pp. 79-86. doi:10.1200/JOP.0723601

[9] Michigan Cancer Consortium Prostate Cancer Action Committee, "Guidelines for Primary Care Management of Prostate Cancer Post-Treatment Sequelae," 2012. http://www.michigancancer.org/PDFs/MCCGuidelines-Pr imaryCareMgtProstateCaPost-TxSequelae.pdf

[10] Michigan Cancer Consortium, "Fact Sheet about Symptoms after Prostate Cancer Treatment," 2012. http://www.prostatecancerdecision.org/MCCfactsheets.ht $\mathrm{m}$

[11] B. T. Allaire, J. G. Trogdon, B. M. Egan, et al., "Measuring the Impact of a Continuing Medical Education Pro- gram on Patient Blood Pressure," The Journal of Clinical Hypertension, Vol. 13, No. 7, 2011, pp. 517-522. doi:10.1111/j.1751-7176.2011.00469.x

[12] D. J. Brimmer, K. K. McCleary, T. A. Lupton, et al., "A Train-the-Trainer Education and Promotion Program: Chronic Fatigue Syndrome-A Diagnostic and Management Challenge," BMC Medical Education, Vol. 8, 2008, pp. 49-58. doi:10.1186/1472-6920-8-49

[13] A. Treiyer, P. Anheuser, Z. Bütow, et al., “A Single Center Prospective Study: Prediction of Postoperative General Quality of Life, Potency and Continence after Radical Retropubic Prostatectomy," Journal of Urology, Vol. 185, No. 5, 2011, pp. 1681-1685. doi:10.1016/j.juro.2010.12.052

[14] M. E. Del Giudice, E. Grunfeld, B. J. Harvey, et al., "Primary Care Physicians' Views of Routine Follow-Up Care of Cancer Survivors," Journal of Clinical Oncology, Vol. 27, No. 20, 2009, pp. 3325-3338. doi:10.1200/JCO.2008.20.4883

[15] D. A. Asch, M. K. Jedrziewski and N. A. Christakis, "Response Rates to Mail Surveys Published in Medical Journals," Journal of Clinical Epidemiology, Vol. 50, No. 10, 1997, pp. 1129-1136. doi:10.1016/S0895-4356(97)00126-1 